\title{
Scale up of a multi-strategic intervention to increase implementation of a school healthy canteen policy: findings of an intervention trial
}

Kathryn L. Reilly ${ }^{1,2,3,4^{*}}$ (D) Nicole Nathan ${ }^{1,2,3,4}$, John Wiggers ${ }^{1,2,3,4}$, Sze Lin Yoong ${ }^{1,2,3,4}$ and Luke Wolfenden ${ }^{1,2,3,4}$

\begin{abstract}
Background: Implementation interventions delivered in schools to improve food provision have been found to improve student diet and reduce child obesity risk. If the health benefits of food availability policies are to be realised, interventions that are effective need to be implemented at scale, across an entire population of schools. This study aims to assess the potential effectiveness of an intervention in increasing the implementation, at scale, of a healthy canteen policy by Australian primary schools.
\end{abstract}

Methods: A non-controlled before and after study was conducted in primary schools located in the Hunter New England region of New South Wales, Australia. Schools received a multi-component intervention adapted from a previous efficacious and cost-effective randomised control trial. The primary trial outcome was the proportion of canteen menus compliant with the state healthy canteen policy, assessed via menu audit at baseline and follow-up by dietitians. Secondary outcomes included policy reach and adoption and maintenance policy implementation.

Results: Of the 173 schools eligible for inclusion in the trial, 168 provided menus at baseline and 157 menus were collected at follow-up. At follow-up, multiple imputation analysis found 35\% (55/157) of schools compared to $17 \%(29 / 168)$ at baseline $(\mathrm{OR}=2.8(1.6-4.7), p=<0.001)$ had menus compliant with the state healthy canteen policy. As an assessment of the impact of the intervention on policy reach, canteen manager and principal knowledge of the policy increased from $64 \%(n=76)$ and 38\% $(n=44)$ respectively at baseline to $69 \%(n=89)$ and $60 \%(n=70)$ at follow-up ( $p=0.393, p=0.026)$. Adoption of the policy increased from $80 \%(n=93)$ at baseline to 90\% ( $n=104)$ at follow-up ( $p=0.005)$ for principals, and from $86 \%(n=105)$ to $96 \%(n=124)(p=0.0001)$ for canteen managers. Multiple imputation analysis showed intervention effects were maintained six-months post intervention (33\% of menus compliant OR $=2.6$ (1.5-4.5), $p=<0.001$ compared to baseline).

Conclusions: This study found school canteen compliance with a healthy food policy increased in association with a multi-strategy intervention delivered at scale. The study provides evidence for public health policy makers and practitioners regarding strategies and modes of support required to support improvement in nutrition policy implementation across entire populations of schools.

Keywords: Implementation, Schools, Nutrition, Policy, Canteen, Scale

\footnotetext{
* Correspondence: kathryn.reilly@hnehealth.nsw.gov.au

${ }^{1} \mathrm{~S} c h o o l$ of Medicine and Public Health, University of Newcastle, Callaghan, NSW 2308, Australia

${ }^{2}$ Hunter Medical Research Institute, Newcastle, NSW 2300, Australia

Full list of author information is available at the end of the article
}

(c) The Author(s). 2018 Open Access This article is distributed under the terms of the Creative Commons Attribution 4.0 International License (http://creativecommons.org/licenses/by/4.0/), which permits unrestricted use, distribution, and reproduction in any medium, provided you give appropriate credit to the original author(s) and the source, provide a link to the Creative Commons license, and indicate if changes were made. The Creative Commons Public Domain Dedication waiver (http://creativecommons.org/publicdomain/zero/1.0/) applies to the data made available in this article, unless otherwise stated. 


\section{Background}

Globally in 2013, 24\% of boys and 23\% of girls were classified as overweight or obese (ages 2-19 years) [1]. Childhood overweight and obesity is a predictor of adult obesity, which is associated with chronic diseases including cardiovascular disease, diabetes and some cancers [2-5]. As a result, the economic costs of overweight and obesity to individuals and society are considerable [6].

Schools are recommended by the World Health Organisation (WHO) as a critical setting to improve public health nutrition and to reduce the risk of unhealthy weight gain in childhood [7]. Given this, policies have been introduced in the school setting in a number of jurisdictions internationally that support the provision of food in line with national dietary guidelines [8, 9]. For example, in the United Kingdom, the Department of Education in 2015 mandated the 'School Food Plan'; a set of standards which requires schools to provide children access to healthy, nutritious meals at school [10]. Similarly, in Australia, where children can purchase foods and drinks over the counter from a canteen or tuckshop [11], all states and territories have introduced mandatory healthy canteen policies that promote the purchase of healthy foods and restrict the sale of less healthy foods [9].

In 2005 in the state of New South Wales (NSW), Australia, the Fresh Tastes @ School Healthy Canteen Strategy was developed and mandated by the Department of Education for government schools to promote the availability of healthy food options in school canteens and limit the sale of foods with poor nutritional value [12]. The policy involves the use of a 'traffic light' system that categorizes canteen menu items based on their nutritional value. Schools are required to have a canteen menu dominated (>50\%) by 'green' (healthier) food options, to limit the availability of 'amber' foods and drinks (less healthy) and to restrict the sale of 'red' (poor nutritional value) items [12]. A 'Sugar Sweetened Drink Ban' restricting the sales of all sugar sweetened drinks was also introduced in NSW in 2007 [12]. Local population health services are responsible for providing policy implementation support to schools as part of usual service delivery practice.

Despite the existence of school nutrition policies and guidelines, international research suggests that most schools fail to implement them $[13,14]$. For example, results of the 2014 School Health Policies and Practices Study in the United States found that $95 \%$ of secondary schools sold sugar sweetened beverages and the percentage of schools where fruit and vegetables were available for purchase was approximately 6\% [15]. Similarly, a 2007 survey of 50 schools in New Zealand found $84 \%$ of schools sold foods in contravention of the guidelines and only $48 \%$ had fruit on the menu [16]. Likewise, Woods et al. (2014) analysed a total of 263 school menus from all states and territories in Australia and found variable compliance with state policies from as low as 5 to $62 \%$ [9] indicating a clear deficit between the existence of school nutrition policy and its implementation. Hills and colleagues (2015) assessed canteen menus in an Australian region over time (2007-2010) and found little improvement in policy adherence [17].

Despite the importance of implementing school nutrition policies, few trials have investigated the effectiveness of strategies that support the scaled-up implementation by schools of nutrition initiatives broadly, and of policies governing the availability of food in school canteens and food service settings specifically. Three randomised controlled trials of varying implementation support intensity have recently been conducted in NSW, Australia, to enhance the implementation of the state-based school healthy canteen policy [18-20]. Specifically, relative to control groups, schools receiving a 'high' intensity implementation support consisting of bi-monthly school visits, executive support, consensus processes, staff training, provision of tools and resources, academic detailing, recognition, performance monitoring and feedback and marketing strategies reported an absolute improvement in menus adherent to the state-based school healthy canteen policy of $56 \%$ (RR $=14.41 ; 95 \%$ CI: 2.08, 99.97, $p=<0.001$ ) [21]. Similarly those receiving a 'medium' intensity implementation support involving similar strategies, in conjunction with a less expensive mode of on-going support (text messaging as oppose to school onsite-visits) reported an absolute improvement of $27 \%(\mathrm{RR}=4.29 ; 95 \% \mathrm{CI}: 1.04,17.68$, $p=0.02$ ) [21]. The implementation support strategies tested in both of these trials were shown to be cost-effective [21].

To our knowledge these controlled trials form part of the very limited evidence base of strategies to improve implementation of healthy canteen policies globally [22]. While the three trials provide evidence of the effectiveness and cost-effectiveness of implementation strategies and modalities that support policy implementation, they were conducted in relatively small numbers of schools (approximately 35 schools per intervention group). If the health benefits of interventions are to be realised, interventions need to be effective when implemented at scale, across an entire population of schools [23, 24]. Scaling up of a proven intervention from small well controlled and defined research studies into population wide implementation presents unique challenges related to workforce capacity, infrastructure limitations, and catering for a greater diversity of implementation contexts, including differences in geographic or socio-economic characteristics [25].

Research suggests program implementation and effectiveness may attenuate as programs are attempted to be 
implemented, in real world contexts, as scaling up effective interventions has been associated with a reduction in the impact of implementation support [26, 27] For example, a randomised trial in Australian childcare services tested an intervention to support implementation of practices recommended to improve child physical activity in 20 services [28]. In the 10 services receiving implementation support, substantial improvements of over $40 \%$ in most instances in practice implementation were evident [28]. A large scale quasi experimental trial, assessed the impact of attempts to implement such practices, at scale, in the same region across 300 childcare services [26]. The implementation strategy was modified slightly to enable delivery at scale, including the removal of on-site visits however, the implementation support was largely ineffective with no significant improvements in eight of the 11 practices targeted [26].

At present, there are no reported trials of strategies to support the implementation of school healthy canteen policies at-scale. To address this evidence gap, the aim of this study is to assess the potential effectiveness of an intervention in increasing the implementation, at scale, of a healthy canteen policy by Australian primary schools.

\section{Methods}

\section{Design and setting}

A non-controlled before and after study, which is acknowledged as an appropriate design for interventions at this scale [29] was conducted in primary schools located in the Hunter New England region of NSW, Australia. The Hunter New England region covers a large geographical region (more than $130,000 \mathrm{~km}^{2}$ ) and consists of a socioeconomically and demographically diverse population of approximately 112,000 children aged 5-12 years [30] and over 400 primary schools.

Approval to conduct the study was obtained from the Hunter New England Human Research Ethics Committee (no. 06/07/26/4.04), The University of Newcastle Human Research Ethics Committee (Approval Number H-2008-0343) as well as the NSW Department of Education and the relevant Catholic Schools Offices.

\section{Sample}

All primary schools (serving children aged 5-12 years) $(n=338)$ in the study region identified via health service record as having an operational canteen were eligible to participate. Schools were ineligible if they catered for secondary students (children aged 13-18 years old), were special purpose schools, that is, catering for students with special needs, juvenile justice or hospitalised, or had already participated in other trials by the research team [18-20, 31].

\section{Recruitment}

Principals of all eligible schools were sent an information letter inviting them to participate in the study. Two weeks following receipt of the invitation, principals were telephoned by a trained research assistant, who confirmed school eligibility, and sought their consent to complete a 20-min Computer-Assisted Telephone Interview regarding school canteen characteristics and policy knowledge and adoption. The interview was conducted during February-April 2016. At the conclusion of interview principal consent was sought to forward an information letter to the school canteen manager inviting them to attend training workshops and to receive support to implement the policy.

\section{Multi-component implementation intervention Theoretical framework}

Rogers' Diffusion of Innovation Theory a framework for designing health prevention innovations at scale was chosen to guide the development of the intervention $[32,33]$. The theory identifies a number of characteristics of an innovation that impact on the rate of adoption by the target population including; the innovation being perceived to have greater advantage over what they are currently doing; be compatible with how they work; be of less complexity; be easily trialled first; and have visible results [32].

\section{Intervention to support implementation at scale}

To facilitate the implementation of the state healthy canteen policy across the population of schools in the study region, a previous efficacious and cost-effective randomised control trial was replicated [19]. In order to address an identified barrier to policy implementation, that being the classification of menu items according to policy guidelines [34] and to enable implementation support across a large geographical area, an online canteen product database was included as an additional strategy [35]. The intervention was delivered in partnership with the local population health service as part of its usual service delivery practice [36]. The intervention was delivered over a nine-month period (Feb-Oct 2016). The intervention strategies involved the following:

1. Leadership support - An information letter was sent to all eligible school principals and canteen managers providing an overview of the state healthy canteen policy requirements and informing them of an upcoming implementation training workshop and resources available. Principals were sent information regarding the training workshop via email and mail and asked to support and encourage the canteen manager and a parent representative to attend the training workshop and to participate in 
receiving ongoing support. Securing leadership support has been associated with implementation success [37].

2. Consensus processes - A consensus process involving the canteen manager, canteen staff and/or parent representative was undertaken [38]. A canteen policy implementation action plan was developed. The action plan outlined the school's goals and key tasks towards implementation of the policy.

3. Education - One-day ( $5 \mathrm{~h}$ ) face to face group training workshops were delivered to canteen managers and parent representatives to provide education and skill development [38] in: categorizing menu items according to the policy guidelines; use of a canteen product database and website; financial management of canteens including stock selection, pricing, promotion and operation; and managing volunteers.

4. Tools and resources - Canteen managers received a manual of resources to facilitate implementation [39] of the state healthy canteen policy including: sample canteen policies; planning templates; pricing guides; online product database instructions; guidelines for small schools and self-assessment forms.

5. Provision of implementation support - Schools received at least one contact per school term by a school support officer (trained dietitian) across the intervention period (minimum of four contacts). Contact was made via email, telephone or text messaging with the aim to review implementation progress, prompt action plan delivery and facilitate problem solving [39].

6. Reinforcement - Throughout the intervention period, schools whose canteens were assessed to be compliant with the state policy received a letter of recognition from the research team to acknowledge their positive change [32].

7. Audit and feedback - Audit and feedback has been shown to produce significant practice changes $[40,41]$ Schools received up to two menu audit and feedback reports regarding canteen progress towards achieving implementation action plan goals (Summer and Winter menus). Canteen menus were collected via school administration personnel and assessed according to the policy criteria. The reports identified menu food and beverage items that were restricted for sale and made suggestions for suitable replacements [42].

8. Canteen product database - a canteen product database was developed and placed on the project website (Good for Kids. Good for Life website) [35] to provide access to a range of potential products coded according to the state healthy canteen policy.

\section{Data collection and measures}

School principals were invited to participate in a telephone interview regarding school characteristics and policy knowledge and adoption at baseline (Feb-Apr 2016) and again immediately post intervention (Nov-Dec 2016). Canteen managers who attended the training workshops were invited to complete a pen-paper survey prior to commencing the training workshops (Feb-Apr 2016). Canteen managers who did not attend the training workshops were contacted via telephone and invited to complete the survey via a computerised assisted telephone interview. All canteen managers were contacted immediately post intervention to complete a follow-up telephone interview (Nov-Dec 2016).

\section{School and canteen characteristics}

Information regarding school size (number of enrolled students), school type (Government, Catholic or Independent) and the locality of the school (school postcode) was collected from school websites and school databases. Canteen characteristics such as days of operation, staffing and management of the canteen were collected through the baseline canteen manager interview.

\section{Exposure to other nutrition interventions}

During the follow-up telephone interview, canteen managers were asked to report any exposure to and/or involvement in other initiatives to assist with the implementation of the policy.

\section{Outcomes}

Assessment of the trial outcomes of the intervention was informed by the RE-AIM evaluation model [43] and involved four of the RE-AIM domains. Implementation of the policy (compliance) was the primary trial outcome. Measures of Reach, Adoption and Maintenance [44] were identified as secondary. We did not re-assess 'effectiveness' of the intervention on dietary outcomes at the level of individual students as that has previously been found to be effective in improving the nutritional quality of foods purchased [20], and the effectiveness of the intervention is supported by a systematic review of experimental research [45].

\section{Primary trial outcome - compliance with the 'Fresh Tastes @ School' policy}

The primary trial outcome was the proportion of canteen menus that were compliant with the state policy [12]: defined as containing no 'red' or 'banned' menu items and having $>50 \%$ 'green' menu items. We also report the proportion meeting each of these two criteria separately. Outcome data were collected at baseline and follow-up via audits of canteen menus faxed or emailed to the project team by the school. Menus were audited 
by a dietitian, trained in menu classification, using a validated Quick Menu Audit tool [46]. The tool consisted of a list of common canteen menu items grouped into categories such as drinks, hot food, frozen dairy treats, snacks, sandwiches and salads. The tool included colour coded classifications and justifications for assumptions made regarding menu item details such as brand and portion size, to categorise menu items as 'green', 'amber', 'red' and 'banned' according to the criteria specified by the state policy.

Menu compliance was determined by tallying all items on the menu, and determining the percentage of items that were categorised as either 'green, 'amber,' 'red' and 'banned'.

\section{Secondary outcomes}

Policy reach As a measure of school exposure to the policy (reach) by assessing awareness of it, principals and canteen managers were asked during telephone interviews, to identify the intent of the state policy. Specifically, principals and canteen managers were asked which one of the following statements they thought was consistent with the policy; "Foods high in saturated fat, salt or excess kilojoules; a) should not be available for regular sale (correct response); b) can be sold regularly but must not comprise more than $10 \%$ of items listed on canteen menus; or c) can be sold regularly but schools must have 2 days per term where such foods are not available".

Policy adoption As a measure of stage of adoption, during the telephone interviews, principals and canteen managers were asked: "Which of the following statements best represents your school's intent to use the Fresh Tastes @ School guidelines?” Based on the Alberta Nutrition Guideline Outcomes Telephone-Survey Questionnaire [47], respondents were asked to categorise their school according to the five stages of behaviour change; 1 . We have not thought about using the Fresh Tastes guidelines in the canteen / Don't know (pre-contemplation); 2. We are thinking about using the Fresh Tastes guidelines in the canteen (contemplation); 3 . We are planning to or have taken some steps to using the guidelines in the canteen (preparation); 4 . We are currently using the Fresh Tastes guidelines (action); or 5. We have been using the Fresh Tastes guidelines for more than 6 months (maintenance) [48]. (Table 3).

Implementation maintenance Maintenance of implementation of the policy, was assessed by measuring compliance (primary outcome), six months after the immediate post-intervention outcome follow-up measure.

\section{Process evaluation}

Project records were used to determine the proportion of schools that: received principal information letters, developed action plans, attended training workshops, received tools and resources, received menu feedback reports, and received on-going support via text messaging or email. Acceptability of the training workshop content was measured through a pen and paper survey conducted at the completion of workshops.

\section{Analyses}

All analyses were conducted using the statistical package SAS 9.3 (SAS Institute Inc., Cary, NC). Descriptive statistics were used to describe the demographic, school and canteen characteristics of the group. The number of enrolled students in each school were used to categorise school size as small (1-159 students), medium (160-450) or large (> 450 students) based on the NSW Department of Education's classifications of school size [49]. School socio-economic status was based on postcode. Similar to other Australian based implementation studies [18-20], 'higher socio-economic status' were those schools ranked in the top 50\% of NSW, whilst 'lower socio-economic' status was the bottom 50\% [50]. School postcode was also used to describe locality; 'rural' defined as outer regional, remote and very remote areas, 'urban' defined as regional cities and inner regional areas [51].

Pre-post differences were assessed using mixed effects logistic regression models to assess the impact of the intervention on the following compliance outcomes; overall compliance, no 'red' items on the menu and greater than $50 \%$ 'green' items, as per policy requirements [12]. Exploratory chi-square analysis was performed to assess whether there was an association between compliance at follow-up and school characteristics. All analyses were performed on complete case data, where schools provided menus at both baseline and follow-up (primary outcome) or maintenance (secondary outcome). Additionally, analyses employing multiple imputation was performed for schools with missing data at either follow-up or maintenance.

Pearson Chi-square tests were used to measure pre-post differences in the measure of 'reach' - proportion of principals and canteen managers who could correctly identify the statement consistent with the policy. For the adoption measure, schools who responded they were in the preparation, action or maintenance stage of change were classified as 'adopters' whilst schools in the pre-contemplation and contemplation stages were classified as 'non-adopters' [52].

\section{Results}

Participants and characteristics

Of the 338 schools in the study region identified as having an operational canteen, 173 schools were deemed 
eligible for participation. Twenty-four schools had secondary students, and 134 had participated in trials conducted by the research team [18-20, 31]. Seven principals reported they had no operational canteen during the baseline telephone interview and were therefore excluded from the study. At baseline 168 (97\%) schools provided their menu for assessment and $125(72 \%)$ principals and $122(71 \%)$ canteen managers completed their respective telephone interviews. At follow-up, 157 schools provided their menu for assessment, eight schools reported they had recently closed their canteen and four refused to participate. The proportion of canteen managers and principals who completed the follow-up telephone interviews was 129 (75\%) and 115 (66\%) respectively.

Table 1 outlines the baseline characteristics of all eligible schools. Small schools $(<160$ students $)(p=0.002)$, schools categorised as being in lower socioeconomic regions $(p=0.01)$ and those located in outer regional or remote areas $(p=0.04)$ were more likely to not provide a menu at follow-up.

\section{Primary trial outcome - compliance with the state policy}

As seen in Table 2, 41\% (64/157) of schools at follow-up had no 'red' or 'banned' menu items compared to $24 \%$ $(41 / 168)$ at baseline $(p=0.002)$ and $72 \%(113 / 157)$ had greater than $50 \%$ 'green' menu items compared to $62 \%$ $(104 / 168)$ at baseline $(p=0.043)$. In terms of overall compliance with the state policy, $35 \%(55 / 157)$ of schools at follow-up compared to $17 \%(29 / 168)$ at baseline $(\mathrm{OR}=2.7(1.6-4.7), p=<0.001)$ had menus compliant with the state heathy canteen policy. A similar effect was found using multiple imputation for missing data $(\mathrm{OR}=2.8(1.6-4.7), p=<0.001)$.

\section{Exploratory analysis}

Exploratory analysis of compliance rates at follow-up based on school and canteen characteristics identified government schools as significantly more likely to have menus compliant with the policy than Catholic or Independent schools $(p=0.049)$. There was no other statistically significant difference between characteristics such as school size $(p=0.779$, geographical location $(p=0.428)$, socio-economic status $(p=0.17)$, canteen management $(p=0.115)$, or days of operation $(p=0.761)$ in terms of compliance at follow-up.

\section{Secondary outcomes}

Policy reach and adoption results are outlined in Table 3. Canteen managers and principals who correctly identified the statement consistent with the policy increased from $64 \%(n=76)$ and $54 \%(n=63)$ respectively at baseline to $69 \%(89)$ and $68 \%(n=79)$ respectively at follow-up $(p=0.38, p=0.034)$. The proportion of canteen managers
Table 1 Baseline characteristics of eligible schools

\begin{tabular}{|c|c|}
\hline Characteristics & $\begin{array}{l}\text { Intervention Group } \\
n=173(\%)\end{array}$ \\
\hline \multicolumn{2}{|l|}{ School Type } \\
\hline Government & $129(75)$ \\
\hline Catholic & $40(23)$ \\
\hline Independent & $4(2)$ \\
\hline \multicolumn{2}{|l|}{ School size } \\
\hline Small (1-159 students) & $77(45)$ \\
\hline Medium (160-450 students) & $81(47)$ \\
\hline Large (450+ students) & $15(9)$ \\
\hline \multicolumn{2}{|l|}{ Urban/Rural region ${ }^{\mathrm{a}}$} \\
\hline Major Cities + Inner Regional & $149(89)$ \\
\hline Outer Regional + Remote Australia & $19(11)$ \\
\hline \multicolumn{2}{|l|}{ Socio-economic index ${ }^{\mathrm{b}}$} \\
\hline Lower Socio-economic areas & $102(61)$ \\
\hline Higher Socio-economic areas & $64(39)$ \\
\hline \multicolumn{2}{|l|}{ Management of canteen } \\
\hline Parent Representative Groups & $105(86)$ \\
\hline Principal / School run & $14(11)$ \\
\hline Contracted external food service & $1(1)$ \\
\hline Contracted off-site caterer & $0(0)$ \\
\hline Other & $2(2)$ \\
\hline \multicolumn{2}{|c|}{ Canteen Staff (may select more than one option) } \\
\hline Paid manager / supervisor & $39(32)$ \\
\hline Paid assistant(s) /workers /parents & $6(5)$ \\
\hline Volunteer manager / supervisor & $56(46)$ \\
\hline Volunteer workers / parents & $109(89)$ \\
\hline Contractor & $0(0)$ \\
\hline Student help & $6(5)$ \\
\hline Other & $2(2)$ \\
\hline \multicolumn{2}{|l|}{ Days of operation } \\
\hline 5 days / week & $55(45)$ \\
\hline 4 days / week & $10(8)$ \\
\hline 3 days / week & $21(17)$ \\
\hline 2 days / week & $9(7)$ \\
\hline 1 day / week & $26(21)$ \\
\hline Less than 1 day / week & $1(1)$ \\
\hline
\end{tabular}

${ }^{a} 5$ missing data

${ }^{6} 7$ missing data

${ }^{c}$ Percentages greater than 100 as participants may select more than one response

who completed the telephone interview classified as 'adopters' increased from $86 \%(n=105)$ at baseline to $97 \%$ $(n=124)$ at follow-up $(p=<0.0001)$. Likewise, the proportion of principals who were classified as 'adopters' increased from $80 \%(n=93)$ at baseline to $90 \%(n=104)$ at follow-up $(p=0.0001)$. Similar effects were seen with 
Table 2 Primary outcome: implementation

\begin{tabular}{|c|c|c|c|c|c|c|}
\hline & \multirow[t]{2}{*}{$\begin{array}{l}\text { Baseline } \\
\text { n (\%) }\end{array}$} & \multirow[t]{2}{*}{$\begin{array}{l}\text { Follow-up } \\
\text { n (\%) }\end{array}$} & \multicolumn{2}{|l|}{$\begin{array}{l}\text { Complete Case } \\
(n=157)\end{array}$} & \multicolumn{2}{|c|}{ Multiple Imputations $(n=168)$} \\
\hline & & & Odds Ratio (95\%Cls) & $p$-value & Odds Ratio (95\%Cls) & $p$-value \\
\hline No red/banned & $41(24)$ & $64(41)$ & $2.4(1.4-3.7)$ & $0.001^{*}$ & $2.3(1.4-3.7)$ & $<0.001^{*}$ \\
\hline$>50 \%$ green & $104(62)$ & $113(72)$ & $1.7(1.0-2.9)$ & $0.043^{*}$ & $1.7(1.0-2.8)$ & 0.05 \\
\hline Overall compliance & $29(17)$ & $55(35)$ & $2.7(1.6-4.7)$ & $<0.001^{*}$ & $2.8(1.6-4.7)$ & $<0.001^{*}$ \\
\hline
\end{tabular}

*Statistically significant

multiple imputation analysis for both policy reach and adoption (Table 3).

Of the 148 schools who provided menus six-months post intervention (implementation maintenance), 33\% ( $n=48$, $\mathrm{OR}=2.4$ (1.4-4.0), $p=0.001$ compared to baseline) had menus that were compliant with the state policy an effect that remained significant following multiple imputation for missing data $(\mathrm{OR}=2.6(1.5-4.5), p=<0.001)$ (Table 4).

\section{Process evaluation}

Table 5 shows the proportion of schools who received each of the implementation strategies. All schools were mailed the principal information letter, sent text messages or emails as part of on-going support, received tools and resources at workshops or mailed to the school, provided with product database information and mailed at least 1 menu feedback report. Almost half (49\%) of schools developed an action plan, half (50\%) attended the training workshops and $75 \%$ supplied a second menu for review and hence received a second menu feedback report.

\section{Exposure to other nutrition interventions}

Canteen managers from 22 schools reported receiving support to assist in implementation of the policy beyond that provided by the trial. Nine of these schools reported receiving educational and promotional material from a multi-faceted program to promote the consumption of fresh fruit and vegetables amongst school-aged children. Three schools reported liaising with other canteen managers, three had gained information from manufacturers or suppliers and the remaining seven schools listed unspecific support such as receiving 'brochures' and 'leaflets'.

\section{Discussion}

This is the first study to assess the potential effectiveness of an intervention to support implementation at scale, by 173 schools, of a healthy canteen policy in Australian primary schools. The findings suggest that a multi-strategy intervention involving leadership, consensus processes, education, resources, audit and feedback, and on-going support in the form of text messages/emails may improve schools' implementation of a healthy school canteen policy at-scale. The study makes a novel contribution to a currently sparse research landscape in the school setting regarding implementation at-scale [24] and provides evidence to support improvement in nutrition policy implementation across populations of schools.

The high level of participation in this study $(91 \%, 157 /$ 173) is consistent with that required by scale-up programs to reach a large proportion of the target population in order to have a public health impact [53]. The size of the change in compliance in this study $(18 \%)$ is similar to the effect sizes in other school based obesity prevention interventions designed to support large numbers of schools' implementation of health promotion programs (13-45\%) [54-57]. The observed change in compliance in this study (18\%) is, however, lower than the effects achieved in the randomised control trial from which the study was adapted (29\% effect size) [19], a finding that is consistent with previous pragmatic studies [26, 27]. Gottfredson et al. (2015) suggests that adaptations or differences in population characteristics may reduce the effects of interventions when delivered at-scale.

Logistical challenges of expanding implementation into larger and more rural geographic areas appeared to have reduced exposure of the schools to the implementation support provided. For example, just 50\% of schools $(n=79)$ attended training and $49 \%$ of schools

Table 3 Secondary outcomes: reach and adoption

\begin{tabular}{|c|c|c|c|c|c|c|c|c|}
\hline $\begin{array}{l}\text { RE-AIM } \\
\text { domain }\end{array}$ & $\begin{array}{l}\text { Canteen } \\
\text { Managers } \\
\text { Baseline } \\
\mathrm{n}(\%)\end{array}$ & $\begin{array}{l}\text { Canteen } \\
\text { Managers } \\
\text { Follow-up } \\
\text { n (\%) }\end{array}$ & $\begin{array}{l}\text { Complete Case } \\
\left(n=99^{\mathrm{a}}, 100^{\mathrm{b}}\right) \\
p \text {-value }\end{array}$ & $\begin{array}{l}\text { Multiple Imputations } \\
(n=122) \\
p \text {-value }\end{array}$ & $\begin{array}{l}\text { Principals } \\
\text { Baseline } \\
\mathrm{n}(\%)\end{array}$ & $\begin{array}{l}\text { Principals } \\
\text { Follow-up } \\
\text { n (\%) }\end{array}$ & $\begin{array}{l}\text { Complete } \\
\text { Case }(n=88) \\
p \text {-value }\end{array}$ & $\begin{array}{l}\text { Multiple Imputations } \\
(n=125) \\
p \text {-value }\end{array}$ \\
\hline Reach & 76 (64) & 89 (69) & 0.38 & 0.41 & $63(54)$ & 79 (68) & $0.034^{*}$ & $0.036^{*}$ \\
\hline Adoption & 105 (86) & 124 (97) & $0.0001^{*}$ & $<0.0001^{*}$ & $93(80)$ & $104(90)$ & $0.0001^{*}$ & $<0.001^{*}$ \\
\hline
\end{tabular}

"Statistically significant, ${ }^{\mathrm{a}}=$ Reach Outcome, ${ }^{\mathrm{b}}=$ Adoption Outcome 
Table 4 Secondary outcomes: maintenance

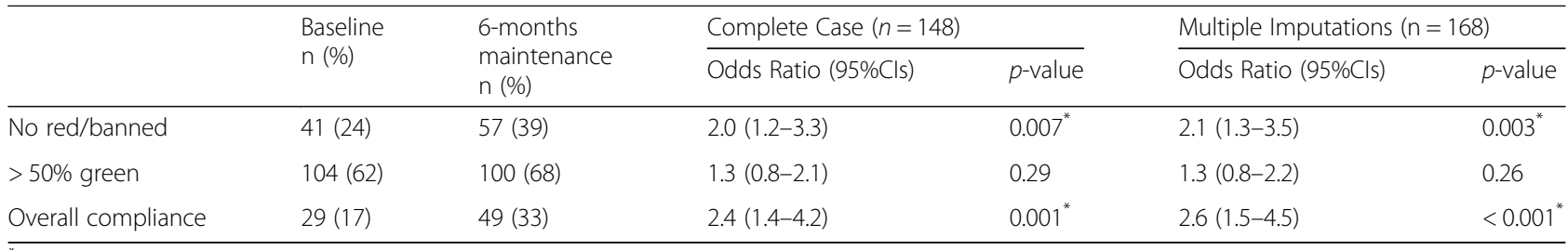

"Statistically significant

developed an action plan $(n=77)$ compared with 93\% $(26 / 28)$ [19] for both in the original trial. Such findings may be due to the greater distances required for school staff to attend training in this trial compared to the original trial. Further research into ways to extend the reach of strategies such as workshops to rural and remote regions, including the possibility of online training [58], may be warranted.

Whilst the policy is strongly endorsed by the Catholic Schools sector in the region and the Association of Independent Schools, it is mandated for government schools only. Government schools were more likely to have menus compliant with the state healthy eating policy $(p=0.049)$ suggesting a positive relationship between a mandatory policy and implementation. There were no other differences in compliance and school characteristics such as location, size or socioeconomic status, indicating that the intervention is effective across a diverse population of schools. Such findings suggest that the policy implementation approach may not further exacerbate existing nutrition inequalities among these groups.

The observed small increases in knowledge of the policy by canteen managers $(5 \%, p=0.393)$ found in this study is unsurprising as the policy was first launched over 10 years ago. Although baseline levels of 'adoption' were similarly high, there was a small but significant shift in schools' adoption of the policy for both canteen managers and principals. The proportion of schools in which an intervention effect was maintained (determined at 6-months post intervention menu audit) (33\%, $n=49)$ was similar to that at immediate post-intervention follow-up $(35 \%, n=55)$. As previous research has shown that policy implementation improves student diet $[20,45,59]$, the findings demonstrates the potential contribution the implementation support strategy can make in achieving public health nutrition enhancements.

Limitations of the study include its non-controlled study design. Whilst the lack of a control group precludes causal inference that the observed changes over time were the result of the intervention, policy implementation over the past decade has remained stable [17] and steps were taken to assess contamination such as any exposure to and/or involvement in other initiatives to assist with implementation of the policy. A further limitation is possible selection bias, as schools that chose to take part in the intervention may be different from those schools that did not [60]. It is not known whether differences existed, for example, in canteen managers' self-motivation and/or support from principals in study participants compared to non-participants.

\section{Conclusion}

Despite the introduction of healthy eating policies in schools in many countries their implementation across the population of schools has been limited. Few trials have investigated the effectiveness of strategies designed to increase schools' implementation of such policies and this study is the first to do so at scale. The study provides novel information for public health policy makers and practitioners regarding strategies and modes of support required to facilitate the implementation of nutrition policies and guidelines broadly and healthy canteen policies specifically across entire jurisdictions.

Table 5 Number of schools receiving implementation strategies

\begin{tabular}{ll}
\hline Implementation Strategy & Number of schools in sample $n=157 \mathrm{n}(\%)$ \\
\hline Principal Information Letter (leadership and buy-in) & $157(100)$ \\
Developed action plan (consensus process) & $77(49)$ \\
Attended training workshop (education) & $79(50)$ \\
Tools and Resources & $157(100)$ \\
Text messages or emails (on-going support) & $157(100)$ \\
Received 1 menu report (audit and feedback) & $157(100)$ \\
Received 2 menu reports (audit and feedback) & $117(75)$ \\
Product database & $157(100)$ \\
\hline
\end{tabular}




\section{Abbreviations}

Cls: Confidence intervals; NSW: New South Wales; OR: Odds ratio; WHO: World Health Organisation

\section{Acknowledgements}

The authors wish to thank Christophe Lecathelinais for the statistical analysis for this manuscript, Melanie Sharpe for contributing to menu audits and all participating schools.

\section{Funding}

The project received infrastructure support from Hunter New England Population Health.

\section{Availability of data and materials}

The datasets used and/or analyzed during the current study are available from the corresponding author on reasonable request.

\section{Authors' contributions}

$\mathrm{KR}, \mathrm{NN}$, and $\mathrm{LW}$ designed the intervention; KR developed intervention materials; KR and NN conducted the research; NN, SY, JW and LW provided overall guidance on implementation and evaluation of the canteen trial in schools; KR contributed to acquisition of data; KR, NN, JW, SY and LW analyzed and interpreted data; KR led the development of the manuscript and all authors contributed to drafts and read and approved the final manuscript.

\section{Ethics approval and consent to participate}

Approval to conduct the study was obtained from the Hunter New England Human Research Ethics Committee (no. 06/07/26/4.04), The University of Newcastle Human Research Ethics Committee (Approval Number H-20080343) as well as the NSW Department of Education and the relevant Catholic Schools Offices.

\section{Consent for publication}

Not applicable

\section{Competing interests}

The authors declare that they have no competing interests.

\section{Publisher's Note}

Springer Nature remains neutral with regard to jurisdictional claims in published maps and institutional affiliations.

\begin{abstract}
Author details
${ }^{1}$ School of Medicine and Public Health, University of Newcastle, Callaghan, NSW 2308, Australia. ${ }^{2}$ Hunter Medical Research Institute, Newcastle, NSW 2300, Australia. ${ }^{3}$ Priority Research Centre for Health Behaviour, University of Newcastle, Newcastle, NSW 2308, Australia. ${ }^{4}$ Hunter New England Population Health, Locked Bag 10, Wallsend, NSW 2287, Australia.
\end{abstract}

\section{Received: 26 March 2018 Accepted: 2 July 2018}

\section{Published online: 11 July 2018}

\section{References}

1. GBD 2013 Risk Factors Collaborators. Global, regional, and national comparative risk assessment of 79 behavioural, environmental and occupational, and metabolic risks or clusters of risks in 188 countries, 19902013: a systematic analysis for the global burden of disease study 2013. Lancet. 2015;386:2287-323.

2. World Health Organisation. World Cancer Report. Int Agency for Research on Cancer. Geneva: WHO; 2014.

3. Kaikkonen JE, Mikkila V, Magnussen CG, Juonala M, Viikari JS, Raitakari OT. Does childhood nutrition influence adult cardiovascular disease risk? insights from the young Finns study. Ann Med. 2013;45(2):120-8.

4. Maynard MGD, Emmett P, Frankel S, Davey Smith G. Childhood diet and adult cancer. Epidemiol Community Health. 2003;57:218-25.

5. Shay CM, Gooding HS, Murillo R, Foraker R. Understanding and improving cardiovascular health: an update on the American Heart Association's concept of cardiovascular health. Prog Cardiovasc Dis. 2015;58(1):41-9.

6. Withrow D, Alter DA. The economic burden of obesity worldwide: a systematic review of the direct costs of obesity. Obes Rev. 2011;2(2):131-41.
7. World Health Organisation. Report of the commission on ending childhood obesity. Geneva: World Health Organisation; 2016.

8. United States Department of Agriculture. Food and Nutrition Service. Nutrition standards in the National School Lunch and school breakfast programs. Fed Regist. 2012;77(17):4087-167.

9. Woods J, Bressan A, Langelaan C, Mallon A, Palermo C. Australian school canteens: menu guideline adherence or avoidance? Health Promot J Aust. 2014;25(2):110 115

10. Public Health England. The Eatwell Guide. Helping you eat a healthy, balanced diet. https://www.gov.uk/government/publications/the-eatwellguide. Accessed 6 Jul 2018.

11. de Silva-Sanigorski A, Breheny $T$, Jones $L$, et al. Government food service policies and guidelines do not create healthy school canteens. Aust N Z J Public Health. 2011;35(2):117-21.

12. NSW Department of Health (DoH) Department of Education and Training (DET). Fresh Tastes @ School NSW Healthy School Canteen Strategy. canteen menu planning guide. 3rd ed. Sydney: NSW DoH, NSW DET; 2012

13. Downs SM, Farmer A, Quintanilha M, et al. From paper to practice: barriers to adopting nutrition guidelines in schools. J Nutr Educ Behav. 2012;44(2): $114-22$.

14. Gabriel CG. de Assis Guedes de Vasconcelos, de Andrade DF, de Abreu Soares Schmitz B. First law regulating school canteens in Brazil: evaluation after seven years of implementation. Arch Latinoam Nutr. 2009;59(2):128-38.

15. U.S. Department of Health and Human Services Centers for disease control and prevention. Results from the School Health Policies and Practices Study 2014. 2015; https://www.cdc.gov/healthyyouth/data/shpps/pdf/shpps-508final 101315.pdf. Accessed 6 Jul 2018.

16. Green Party of Aotearoa New Zealand. Annual tuckshop survey shows pies, Chips still staples. 2007; https://www.foe.org.nz/2007/06/12/nz-schools-to-sell-healthyfood/. Accessed 6 Jul 2018.

17. Hills A, Nathan N, Robinson K, Fox D, Wolfenden L. Improvement in primary school adherence to the NSW healthy school canteen strategy in 2007 and 2010. Health Promot J Austr. 2015;

18. Yoong SL, Nathan N, Wolfenden L, et al. CAFE: a multicomponent audit and feedback intervention to improve implementation of healthy food policy in primary school canteens: a randomised controlled trial. Int J Behav Nutr Phys Act. 2016;13(1):126.

19. Nathan $\mathrm{N}$, Yoong SL, Sutherland $\mathrm{R}$, et al. Effectiveness of a multicomponent intervention to enhance implementation of a healthy canteen policy in Australian primary schools: a randomised controlled trial. Int J Behav Nutr Phys Act. 2016;13(1):106.

20. Wolfenden L, Nathan N, Janssen LM, et al. Multi-strategic intervention to enhance implementation of healthy canteen policy: a randomised controlled trial. Implement Sci. 2017;12(1):6.

21. Reilly KL, Reeves P, Deeming S, Yoong SL, Wolfenden L, Nathan N, Wiggers $J$. Economic analysis of three interventions of different intensity in improving school implementation of a government healthy canteen policy in Australia: costs, incremental and relative cost effectiveness. BMC Public Health. 2018 Dec;18(1):378.

22. Wolfenden L, Nathan N, Sutherland R, et al. Strategies for enhancing the implementation of school-based policies or practices targeting risk factors for chronic disease. Cochrane DB Syst Rev. 2017(11):Art. No.: CD011677.

23. Rychetnik L, Bauman A, Laws $R$, et al. Translating research for evidencebased public health: key concepts and future directions. J Epidemiol Community Health 2012:jech-2011.

24. Glasgow RE, Klesges LM, Dzewaltowski DA, Bull SS, Estabrooks P. The future of health behavior change research: what is needed to improve translation of research into health promotion practice? Ann Behav Med. 2004;27(1):3.

25. Milat AJ, King L, Newson R, et al. Increasing the scale and adoption of population health interventions: experiences and perspectives of policy makers, practitioners, and researchers. Health Res Policy Syst. 2014;12:18

26. Finch $\mathrm{M}$, Wolfenden $\mathrm{L}$, Falkiner $\mathrm{M}$, et al. Impact of a population based intervention to increase the adoption of multiple physical activity practices in Centre based childcare services: a quasi-experimental, effectiveness study. Int J Behav Nutr Phys Act 2012;29;9(1):101.

27. Yoong SL, Wolfenden L, Clinton-McHarg T, et al. Exploring the pragmatic and explanatory study design on outcomes of systematic reviews of public health interventions: a case study on obesity prevention trials. J Public Health (Oxf). 2014;36(1):170-6.

28. Finch $\mathrm{M}$, Wolfenden $\mathrm{L}$, Morgan PJ, Freund $\mathrm{M}$, Jones J, Wiggers J. A cluster randomized trial of a multi-level intervention, delivered by service staff, to 
increase physical activity of children attending center-based childcare. Prev Med. 2014;58:9.

29. Bauman A, Nutbeam D. Evaluation in a nutshell. McGraw-hill education Australia; 2013.

30. Health Stats NSW. Population growth by local Health District. 2014. http:// www.healthstats.nsw.gov.au/Indicator/dem_pop_Ihnmap/dem_pop_Ihn_ snap. Accessed 6 Jul 2018.

31. Delaney T, Wyse R, Yoong SL, et al. Cluster randomised controlled trial of a consumer behaviour intervention to improve healthy food purchases from online canteens: study protocol. BMJ Open. 2017;7(4):e014569.

32. Rogers EM. Diffusion of preventive innovations. Addict Behav. 2002;27:989-93.

33. Owen N, Glanz K, Sallis JF, Kelder SH. Evidence-based approaches to dissemination and diffusion of physical activity interventions. Am J Prev Med. 2006;31(Suppl 4):S35-44.

34. Ardzejewska K, Tadros R, Baxter D. A descriptive study on the barriers and facilitators to implementation of the NSW (Australia) healthy school canteen strategy. Health Educ J. 2012;72(2):136-45.

35. Good for Kids.Good for Life; Canteen Product Database http://www. goodforkids.nsw.gov.au/primary-schools/canteens/product-search/. Accessed 6 Jul 2018

36. Wolfenden $\mathrm{L}$, Yoong $\mathrm{SL}$, Williams $\mathrm{CM}$, et al. Embedding researchers in health service organizations improves research translation and health service performance: the Australian hunter New England population health example. J Clin Epidemiol. 2017;85:3-11. https://doi.org/10.1016/j.jclinepi. 2017.03.007.

37. Rohrbach LA, Grana R, Sussman S, Valente TW. Type II translation: transporting prevention interventions from research to real-world settings. Evaluation Health Prof. 2006;29(3):302-33.

38. Forsetlund L, Bjørndal A, Rashidian A, et al. Continuing education meetings and workshops: effects on professional practice and health care outcomes. Cochrane Database Syst Rev. 2009;2:CD003030.

39. Karuza J. Enhancing physician adoption of practice guidelines: dissemination of influenza vaccination guideline using a small-group consensus process. Arch Intern Med. 1995;155(6):625-32.

40. Ivers N, Jamtvedt G, Flottorp S, et al. Audit and feedback: effects on professional practice and healthcare outcomes. Cochrane Database Syst Rev. 2012;6(6)

41. Alvero A, Bucklin BR, Austin A. An objective review of the effectiveness and essential characteristics of performance feedback in organizational settings (1985-1998). J Organ Behav Manag. 2001;21:1-28.

42. Brehaut JC, Colquhoun HL, Eva KW, et al. Practice feedback interventions: 15 suggestions for optimizing effectiveness practice feedback interventions. Ann Intern Med. 2016;164(6):435-41.

43. Glasgow RE, Vogt TM, Boles SM. Evaluating the public health impact of health promotion interventions: the RE-AIM framework. Am J Public Health. 1999;89(9):1322-7.

44. Glasgow RE, Klesges LM, Dzewaltowski DA, Estabrooks PA, Vogt TM. Evaluating the impact of health promotion programs: using the RE-AIM framework to form summary measures for decision making involving complex issues. Health Educ Res. 2006;21 (5):688-94.

45. Jaime PC, Lock K. Do school based food and nutrition policies improve diet and reduce obesity? Prev Med. 2009:48(1):45-53.

46. Reilly $\mathrm{K}, \mathrm{Nathan} \mathrm{N}$, Wolfenden $\mathrm{L}$, et al. Validity of four measures in assessing school canteen menu compliance with state-based healthy canteen policy. Health Promot J Aust. 2017;27(3):215-21.

47. Olstad DL, Lieffers JR, Raine KD, McCargar LJ. Implementing the Alberta nutrition guidelines for children and youth: in a recreational facility. Can J Diet Pract Res. 2011;72(4):e212-20.

48. Prochaska JO. Transtheoretical model of behavior change. In encyclopedia of behavioral medicine. Springer New York. 2013:1997-2000.

49. New South Wales Department of Education and Training. DET directory. Sydney. NSW: Department of Education and Training; 2009. p. 2009.

50. Australian Bureau of Statistics. Technical paper: census of population and housing: socioeconomic indexes for Australia (SEIFA). In: Cat. No 2039.0.55. 001. Canberra: Commonwealth of Australia; 2006. http://www.abs.gov.au/ ausstats/abs@.nsf/mf/2039.0.55.001. Accessed 6 Jul 2018.

51. Australian Bureau of Statistics. Australian Standard Geographical Classification (ASGC). In: Cat. no 1216.0. Canberra: Commonwealth of Australia; 2011. http://www.abs.gov.au/ausstats/abs@.nsf/mf/1216.0. Accessed 6 Jul 2018.
52. Downs SM, Farmer A, Quintanilha M, et al. Alberta nutrition guidelines for children and youth: awareness and use in schools. Can J Diet Pract Res. 2011;72(3):137-40

53. Gottfredson DC, Cook TD, Gardner FE, et al. Standards of evidence for efficacy, effectiveness, and scale-up research in prevention science: next generation. Prev Sci. 2015;16(7):893-926.

54. Hoelscher DM, Kelder SH, Murray N, Cribb PW, Conroy J, Parcel GS. Dissemination and adoption of the child and adolescent trial for cardiovascular health (CATCH): a case study in Texas. J Public Health Manag Pract. 2001;7(2):90-100.

55. Rohrbach LA, Graham JW, Hansen WB. Diffusion of a school-based substance abuse prevention program: predictors of program implementation. Prev Med. 1993;22(2):237-60

56. Nathan $\mathrm{N}$, Wolfenden $\mathrm{L}$, Bell AC, et al. Effectiveness of a multi-strategy intervention in increasing the implementation of vegetable and fruit breaks by Australian primary schools: a non-randomized controlled trial. BMC Public Health. 2012;12:651.

57. Fagan AA, Mihalic S. Strategies for enhancing the adoption of school-based prevention programs: lessons learned from the blueprints for violence prevention replications of the life skills training program. J Community Psychology. 2003;31(3):235-53.

58. Erickson AS, Noonan PM, McCall Z. Effectiveness of online professional development for rural special educators. Rural Special Education Quarterly. 2012;31(1):22-32.

59. Masse LC, de Niet-Fitzgerald JE, Watts AW, Naylor PJ, Saewyc EM. Associations between the school food environment, student consumption and body mass index of Canadian adolescents. Int J Behav Nutr Phys Act. 2014;11(1):29.

60. Schildmann EK, Higginson IJ. Evaluating psycho-educational interventions for informal carers of patients receiving cancer care or palliative care: strengths and limitations of different study designs. Palliat Med. 2011;25(4): $345-56$.

\section{Ready to submit your research? Choose BMC and benefit from:}

- fast, convenient online submission

- thorough peer review by experienced researchers in your field

- rapid publication on acceptance

- support for research data, including large and complex data types

- gold Open Access which fosters wider collaboration and increased citations

- maximum visibility for your research: over $100 \mathrm{M}$ website views per year

At BMC, research is always in progress.

Learn more biomedcentral.com/submissions 